\title{
OPEN Dual effects of 9-cis retinoic acid on ACTH-dependent hyperplastic adrenal tissues
}

\author{
Francesca Pecori Giraldi ${ }^{1,2}$, Antonella Sesta ${ }^{2}$, Laura Tapella ${ }^{2}$, Maria Francesca Cassarino ${ }^{2} \&$ \\ Luigi Castelli ${ }^{3}$
}

Retinoids play a pivotal role in adrenal development and differentiation. Recent clinical trials revealed therapeutic potential of both all-trans and 9-cis retinoic acid in patients with cortisol excess due to a pituitary ACTH-secreting adenoma and indicated that retinoids might act also on the adrenal. Aim of the present study was to evaluate the effect of 9-cis retinoic acid on adrenals from patients with ACTH-dependent Cushing's syndrome. Adrenal specimens from six patients with Cushing's disease were incubated with $10 \mathrm{nM}-1 \mu \mathrm{M}$ 9-cis retinoic acid with and without $10 \mathrm{nM} \mathrm{ACTH}$. Cortisol secretion was measured by immunoassay and expression of genes involved in steroidogenesis as well as retinoic acid action were evaluated by real-time RT-PCR. Incubation with 10-100 nM 9-cis retinoic acid increased spontaneous cortisol secretion and expression of STAR and CYP17A. On the other hand, in wells treated with $A C T H, 9-c i s$ retinoic acid markedly diminished $A C T H$ receptor upregulation and no stimulatory effect on cortisol secretion or steroidogenic enzyme synthesis was observed. ACTH itself increased ligand-induced retinoic acid receptor expression, possibly enhancing sensitivity to retinoic acid. Our findings indicate that the effect of 9-cis retinoic acid in presence of ACTH is distinct from unchallenged wells and support the hypothesis of a direct adrenal action in patients with Cushing's disease.

Retinoids are critical for embryonal organogenesis, in particular neural crest and mesoderm-derived organs including the adrenal gland. Several lines of evidence support the role of retinoids in early stage adrenal differentiation ${ }^{1}$ and zona fasciculata organization ${ }^{2}$. In adult life, retinoids are known to exert an antiproliferative effect in a variety of cells, including skin, breast and neuronal cells ${ }^{3}$, and currently play a role in treatment of acute promyelocytic leukemia ${ }^{4}$ and possibly other tumors, such as, neuroblastoma, breast cancer, melanoma, ${ }^{3}$. Retinoic acid has also been tested in adrenal cancer and shown to modulate corticosteroid secretion and cell proliferation ${ }^{5,6}$.

Most recently, retinoids have been proposed for the treatment of Cushing's disease, a severe endocrine disorder caused by an excess cortisol secretion due to a pituitary corticotropin (ACTH)-secreting tumor ${ }^{7}$. In vitro studies revealed that all-trans retinoic acid as well as the 9-cis derivate inhibit proliferation in a murine corticotrope tumor cell line and blunt ACTH secretion in human corticotrope adenomas ${ }^{5,8-10}$. Our pilot study in patients with Cushing's disease revealed that all-trans retinoic acid (tretinoin) administration is beneficial in these patients ${ }^{11}$ and a subsequent study with the 13-cis isomer isotretinoin confirmed these promising results ${ }^{12}$. In detail, administration of tretinoin or isotretinoin reduced markers of cortisol excess in all patients and normalization of urinary free cortisol levels was achieved in approximately $30 \%$ of patients ${ }^{11,12}$. Amelioration of clinical parameters of Cushing's disease, e.g., blood pressure, weight, glucose control, hirsutism, was also observed during tretinoin or isotretinoin treatment ${ }^{11,12}$.

Interestingly, the decrease in cortisol secretion during either retinoid was more pronounced that the change in ACTH levels. While this phenomenon is not uncommon in patients with Cushing's disease treated with pituitaryacting drugs ${ }^{13,14}$, it could be due to a direct action on adrenal glands. In our first study on normal adrenal cortex tissue, we observed a dual effect of 9-cis retinoic acid: stimulation of cortisol secretion and STAR expression by roughly 1.5 -fold on one side and halving of ACTH receptor synthesis on the other ${ }^{15}$. We thus hypothesized that the efficacy of retinoids in Cushing's disease could also be due to a direct effect on the adrenal gland and decided to test this hypothesis in hyperplastic adrenal tissue from these patients.

${ }^{1}$ Department of Clinical Sciences and Community Health, University of Milan, 20122 Milan, Italy. ${ }^{2}$ Neuroendocrinology Research Laboratory, Istituto Auxologico Italiano IRCCS, Via Zucchi 18, 20095 Cusano Milanino, MI, Italy. ${ }^{3}$ Ospedale San Carlo, Reparto di Chirurgia, 20037 Paderno Dugnano, MI, Italy. ${ }^{\square}$ email: francesca.pecorigiraldi@unimi.it 
Aim of the present study was to assess the effects of 9-cis retinoic acid on cortisol secretion and on genes involved in steroidogenesis and retinoid action in adrenal glands from patients with Cushing's disease. In detail, we evaluated 17hydroxylase, StAR (steroidogenic acute regulatory protein), hormone-sensitive lipase E (LIPE), the ACTH receptor (MC2R), as well as known retinoid target genes, such as retinoic acid receptors alpha and beta, liver X receptor (LXR), peroxisome proliferator activated receptor delta (PPARD), chicken ovoalbumin upstream promoter transcription factor 1 (COUP-TF1), sterol regulatory element binding transcription factor 1 (SREBP1), mitochondrial dehydrogenases mND1 and mND6, and genes involved in both pathways, e.g., dosage-sensitive sex-reversal adrenal hypoplasia critical region in the $\mathrm{X}$ chromosome (DAX-1) and steroidogenic factor 1 (SF-1).

\section{Results}

9-cis Retinoic acid increased cortisol secretion in adrenal primary cultures from patients with ACTH-dependent Cushing's syndrome. Cortisol concentrations on average doubled with respect to control wells for both $10 \mathrm{nM}$ and $100 \mathrm{nM} 9$-cis retinoic acid (Fig. 1a, both $\mathrm{p}<0.05$ ); a lesser increase in cortisol was observed with $1 \mu \mathrm{M} 9$-cis retinoic acid (Fig. 1a). 9-cis Retinoic acid also increased expression of StAR and CYP17A (Fig. 1b), and decreased NROB1 (DAX1, Table 1) compared to untreated wells.

As regards the expression of genes related to the retinoic acid pathway, 9-cis retinoic acid increased the expression of both retinoic acid receptor alpha and beta and the transcription factor SREBP1 (Fig. 1c). No significant changes during 9-cis retinoic acid treatment were observed for other factors involved in steroidogenesis, e.g., MC2R, SF-1, LIPE or in retinoic acid action, e.g., liver X receptor, PPARD, COUP-TF1 and the mitochondrial dehydrogenases, i.e., $m t-N D 1, m t-N D 6$, (Table 1), compared to control samples.

As expected, incubation with ACTH increased cortisol secretion $(335.79 \pm 134.64 \%$ control, $\mathrm{p}<0.05 v s$ unchallenged wells) and induced the expression of CYP17A1, LIPE, MC2R and StAR. Interestingly, ACTH also induced $R A R B$ gene expression; no other retinoid acid-related gene was modified during ACTH incubation (Table 1).

9-cis Retinoic acid blunted ACTH-stimulated MC2R expression by roughly $50 \%$ (Fig. $2 \mathrm{~b}$ ) and did not affect the ACTH-induced cortisol response (Fig. 2a) nor ACTH-induced changes in CYP17A and StAR (Fig. 2b). This was replicated at analysis of gene expression normalized to control wells, as the changes in steroidogenic gene expression during retinoic acid-ACTH co-incubated wells were comparable to wells incubated with ACTH alone (Table 1). As regards modulation of retinoic acid receptors, expression of RARA and RARB expression was further enhanced by retinoic acid in ACTH-stimulated wells (Fig. 2c; Table 1). No significant changes compared to ACTH alone were observed for the genes involved in retinoic acid action (NR1H3, PPARD, NR2F1, mt-ND1 and $m t$-ND6, Table 1$)$.

We analysed cortisol secretion during ACTH/retinoid co-incubation by two approaches: the effect of 9-cis retinoic acid on the cortisol response to ACTH was compared to cortisol leves with $10 \mathrm{nM}$ ACTH and the retinoid (10 nM: $92.2 \pm 12.8 \%$ ACTH; 100 nM: $115.3 \pm 16.8 \%$ ACTH; $1 \mu \mathrm{M}$ : 123.6 $\pm 13.3 \%$ ACTH, all comparisons N.S., Fig. 2a) and to cortisol levels with each 9-cis retinoic acid concentration without ACTH (10 nM: $112.9 \pm 13.7 \%$ RA; $100 \mathrm{nM}$ : $144.6 \pm 28.1 \% \mathrm{RA} ; 1 \mu \mathrm{M}$ : $158.6 \pm 32.5 \% \mathrm{RA}$, all comparisons N.S.); of note, the expected increase in cortisol levels with ACTH is over $300 \%$ of unchallenged wells (see above).

\section{Discussion}

Retinoids are known modulators of adrenal embryonic development ${ }^{1,16,17}$ but effects appear to extend beyond adrenal organogenesis. All-trans and 9-cis retinoic acid have been shown to stimulate steroidogenesis in both adrenal and gonadal murine models ${ }^{18-20}$. Conversely, these retinoid agonists proved inhibitors of corticosteroid secretion and adrenal cell proliferation in mouse and human neoplastic adrenal cell lines $\mathrm{s}^{5,6}$; on note, retinoic acid signalling pathway stands out in adrenal tumor microarray and miRNA analysis ${ }^{21}$. Retinoids act mainly via homo- or heterodimerization of ligand-activated RAR and RXR receptors with all-trans retinoic acid and 13-cis retinoic acid acting as RAR agonists and 9-cis retinoic acid binding both RAR and RXR ${ }^{3}$. These receptors may also heterodimerize with other nuclear receptors, such as PPAR gamma and LXR, or act-as has been shown for 9-cis retinoic acid- on mitochondrial RXRs ${ }^{22}$, thus adding an additional layer of complexity to retinoid action.

Retinoids has also been shown to affect tumoral corticotrope cells, corticotropes being the main regulators of adrenal cortisol secretion. In fact, studies on both the murine corticotrope cell line AtT-20 and in human adenomatous corticotrope primary cultures ${ }^{5,8-10}$ revealed that both all-trans and 9-cis retinoic acid can inhibit ACTH synthesis and secretion. Both bone morphogenic protein 4 (BMP4), a transcription factor involved in pituitary tumorigenesis, and COUP-TFI, a negative regulator of retinoic acid response pathways, modulated the action of all-trans and 9-cis retinoic acid action in tumoral corticotropes ${ }^{5,8,23}$. Interestingly, long term (48-192 h) incubation of AtT-20 cells with tambicarotene (Am80), a synthetic RAR alfa and beta agonist, revealed increased ACTH secretion as well as Pomc and Tpit expression ${ }^{24}$; at $24 \mathrm{~h}$-the time frame evaluated in other experiments $^{5,8-10}$ - tambicarotene did not affect ACTH secretion and Pomc secretion, suggesting different involvement of RARs and RXR over time.

This evidence led to clinical trials with tretinoin and isotretinoin in patients bearing an ACTH-secreting pituitary adenoma, i.e., Cushing's disease ${ }^{11,12}$, with promising results. So far, over 20 patients with this severe endocrine disorder have been tested and contaiment of cortisol excess could be observed in up to one third of patients, much like it occurs with other pituitary-acting drugs ${ }^{13,14}$. Interestingly, although the rationale for efficacy of retinoids in these patients rests on evidence collected on the tumoral corticotrope-thus inhibition of ACTH is expected to drive the reduction in adrenal secretion-, the decrease in cortisol levels appeared more pronounced and not strictly parallel to ACTH concentrations. This has been shown to occur with other drugs aimed at the pituitary but, given the known link between retinoids and the adrenal gland, could also be due to a direct action on adrenal cortex cells. 

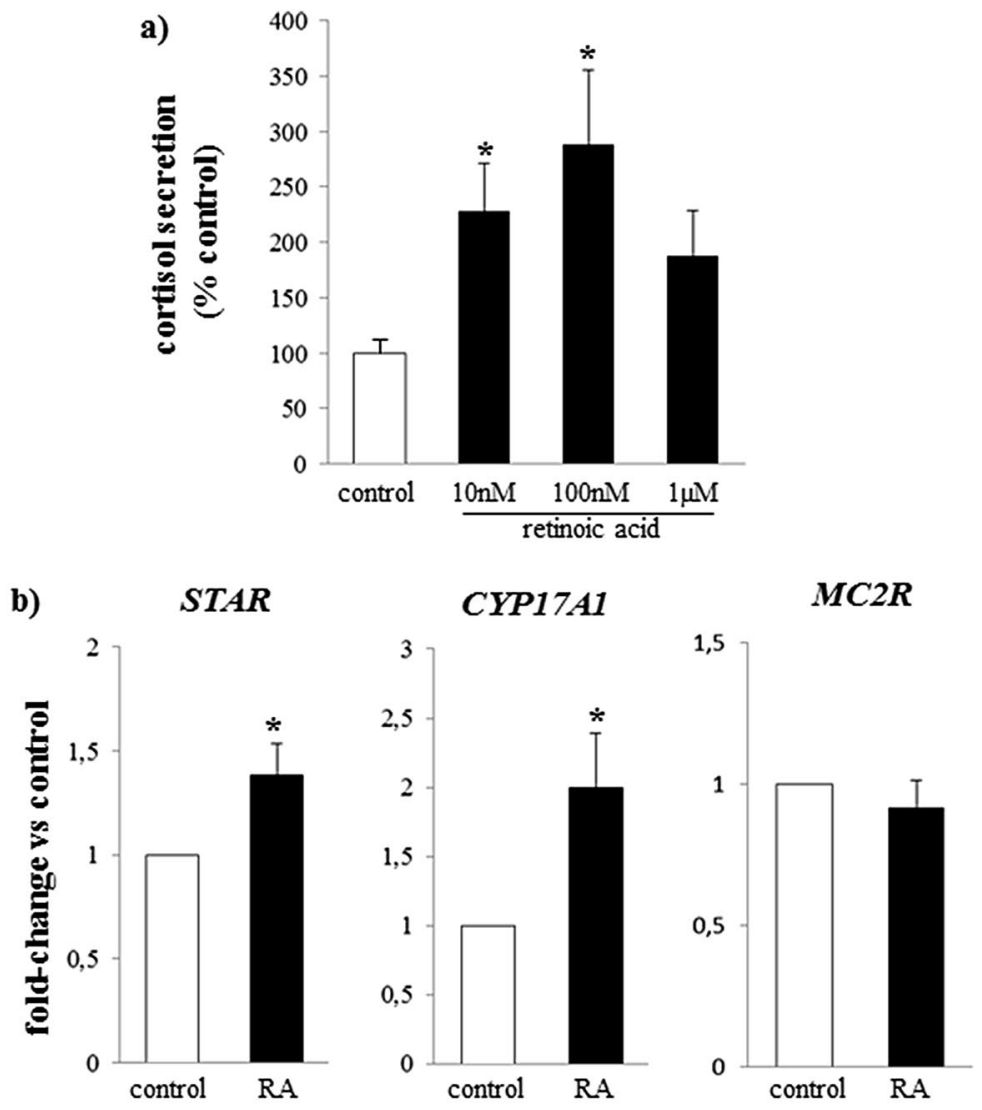

c)

$\boldsymbol{R A R B}$

\section{$\boldsymbol{R A R A}$}

SREBP1
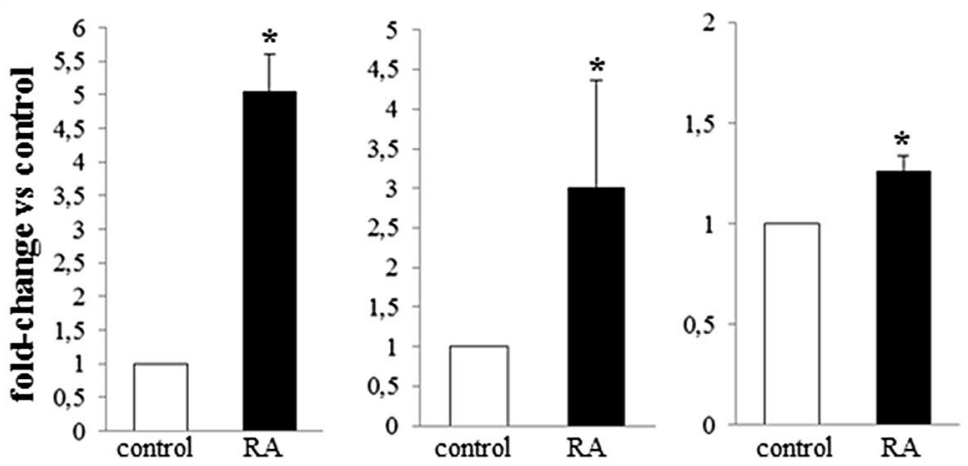

Figure 1. Effect of 9-cis retinoic acid on baseline cortisol secretion and gene expression in adrenal cultures from patients with Cushing's disease. (a) Mean cortisol secretion after $24 \mathrm{~h}$ incubation with $10 \mathrm{nM}-1 \mu \mathrm{M} 9$-cis retinoic acid; (b) expression of STAR, CYP17A1 and $M C 2 R$ after $24 \mathrm{~h}$ incubation with $10 \mathrm{nM}$ 9-cis retinoic acid (RA); (c) expression of RARA, RARB and SREBP1 after $24 \mathrm{~h}$ incubation with $10 \mathrm{nM} 9$-cis retinoic acid (RA). Data is expressed relative to untreated, control wells: equal to $100 \%$ for cortisol secretion and equal to 1 for gene expression. White bar: control, black bars: 9 -cis retinoic acid (RA). ${ }^{*} \mathrm{p}<0.05$ vs control.

We therefore decided to pursue this avenue of investigation and tested 9-cis retinoic acid first in normal human adrenal tissue. Our study demonstrated that 9-cis retinoic acid stimulates spontaneous cortisol secretion as well as synthesis of $S T A R^{15}$, the rate limiting enzyme for adrenal cholesterol availability, in adrenal cells. At the same time, 9-cis retinoic acid markedly blunted expression of the ACTH receptor, i.e., melanocortin type 2 receptor MC2R, and reduced upregulation of $M C 2 R$ induced by ACTH itself. The effects of 9-cis retinoic acid on adrenals appeared therefore two-fold: enhancement of spontaneous cortisol secretion and reduction of the ACTH receptor synthesis, suggesting a modulatory role in intraadrenal negative feedback regulation.

In patients with Cushing's disease, adrenals are continuously exposed to elevated ACTH levels and it stands to reason that the effect of 9-cis retinoic acid on ACTH receptor expression may come to play a major role. Of note, long-standing exposure to excess ACTH usually leads to the development of hyperplastic adrenals in these patients $^{25}$, attesting to the preeminent role of ACTH on adrenal secretion and trophism. Given the above, we 
\begin{tabular}{|l|l|l|l|}
$10 \mathrm{nM}$ ACTH & $10 \mathrm{nM}$ retinoic acid\# & retinoic acid $+\mathrm{ACTH} \#$ & retinoic acid $+\mathrm{ACTH}^{\wedge}$
\end{tabular}

Genes involved in adrenal steroidogenesis

\begin{tabular}{|l|l|l|l|l|}
\hline CYP17A1 & $3.38 \pm 0.763^{*}$ & $2.00 \pm 0.393^{*}$ & $4.56 \pm 1.204$ & $1.48 \pm 0.198$ \\
\hline STAR & $2.06 \pm 0.306^{*}$ & $1.38 \pm 0.149^{*}$ & $2.30 \pm 0.277$ & $1.38 \pm 0.440$ \\
\hline NR5A1 (SF-1) & $1.26 \pm 0.215$ & $0.96 \pm 0.076$ & $0.96 \pm 0.160$ & $0.89 \pm 0.172$ \\
\hline LIPE & $3.12 \pm 0.596^{*}$ & $1.26 \pm 0.220$ & $2.25 \pm 0.949$ & $0.85 \pm 0.091$ \\
\hline NR0B1 (DAX-1) & $1.00 \pm 0.210$ & $0.83 \pm 0.131^{*}$ & $0.82 \pm 0.086$ & $1.00 \pm 0.089$ \\
\hline MC2R & $4.42 \pm 1.034^{*}$ & $0.92 \pm 0.095$ & $2.62 \pm 0.58 \S$ & $0.58 \pm 0.037 \S$ \\
\hline Genes involved in retinoic acid action & \multicolumn{5}{|l|}{} \\
\hline RARA & $1.44 \pm 0.610$ & $3.02 \pm 1.352^{*}$ & $2.25 \pm 0.949 \S$ & $1.36 \pm 0.152 \S$ \\
\hline RARB & $2.06 \pm 0.195^{*}$ & $5.09 \pm 0.540^{*}$ & $5.07 \pm 0.580 \S$ & $2.67 \pm 0.258 \S$ \\
\hline NR2F1 (COUP-TF1) & $1.10 \pm 0.170$ & $0.83 \pm 0.150$ & $0.90 \pm 0.155$ & $0.82 \pm 0.162$ \\
\hline PPARD & $1.06 \pm 0.271$ & $0.95 \pm 0.096$ & $1.06 \pm 0.081$ & $1.02 \pm 0.124$ \\
\hline NR1H3 (LXRalfa) & $1.02 \pm 0.174$ & $1.32 \pm 0.260$ & $1.32 \pm 0.174$ & $1.22 \pm 0.213$ \\
\hline SREBP1 & $1.12 \pm 0.235$ & $1.26 \pm 0.076^{*}$ & $0.93 \pm 0.225$ & $0.93 \pm 0.192$ \\
\hline mt-ND-1 & $1.50 \pm 0.410$ & $1.33 \pm 0.243$ & $1.66 \pm 0.292$ & $1.13 \pm 0.079$ \\
\hline mt-ND-6 & $0.80 \pm 0.208$ & $1.03 \pm 0.127$ & $0.87 \pm 0.233$ & $0.92 \pm 0.107$ \\
\hline
\end{tabular}

Table 1. Gene expression in adrenal cultures from patients with Cushing's disease. ${ }^{~}$ fold change relative to control wells; ^ fold change relative to ACTH-stimulated wells; ${ }^{\star} \mathrm{p}<0.05$ vs untreated wells; $\$ \mathrm{p}<0.05$ vs ACTHtreated wells. Data is expressed as mean \pm S.E.M.

decided to expand upon our previous findings and investigate the effect of 9-cis retinoic acid on adrenals from patients with Cushing's disease.

Incubation with 9-cis retinoic acid led to doubling of spontaneous cortisol secretion in primary cultures established from adrenal tissues collected patients with Cushing's disease, indicating that the stimulatory effect observed in normal adrenal tissue ${ }^{15}$ is mantained in hyperplastic adrenal cortex. Ancillary to increased cortisol secretion, we observed an increase in STAR expression-thereby enhancing cholesterol flux to the mitochondrion ${ }^{26}$ - in keeping with results obtained with all-trans and 9-cis retinoic acid on gonadal and adrenal steroidogenic cell models ${ }^{15,19}$. 9-cis Retinoic acid also increased CYP17A1 expression, thus potentiating microsomial steroidogenesis; similar results have been reported with all-trans retinoic acid in a murine tumoral Leydig cell line ${ }^{27}$. As regards the first enzyme of the steroidogenic cascade, cholesterol side-chain cleavage or P450SCC, a primary target of ACTH stimulation, no changes in CYP11A1 expression or protein levels with either retinoid have been reported by $\mathrm{us}^{15}$ and other investigators ${ }^{18,27}$.

9-cis Retinoic acid also acted upon known targets such as its own receptors, $R A R A$ and $R A R B^{28}, D A X-1$, a transrepressor crucial to adrenal development ${ }^{17}$, and $S R E B P-1$, a sterol regulatory element ${ }^{29}$. Of note, DAX-1 is a major inhibitor of $S T A R^{30}$ and both $S T A R^{31}$ and $C Y P 17 A 1^{32}$ are modulated by SREBP-1. Altogether, this evidence suggests that 9-cis retinoic acid stimulates cortisol secretion via a concerted involvement of DAX-1, SREBP-1, STAR and CYP17A1 in hyperplastic adrenal cells.

In contrast, the most striking effect observed during 9-cis retinoic acid and ACTH co-incubation was the marked reduction in ligand-induced upregulation of the ACTH receptor ${ }^{33-35}$. The ACTH receptor is crucial to cortisol secretion, indeed, mutations in $M C 2 R$ are associated with severe and often fatal cortisol deficiency ${ }^{36}$. In this context, our findings on $M C 2 R$ in hyperplastic adrenal tissues collected from patients with Cushing's disease confirm and extend results obtained during ACTH stimulation in normal adrenals ${ }^{15,34,35}$ : in addition to $M C 2 R$, ACTH proved a strong inducer of STAR, CYP17A1 and LIPE, the hormone-sensitive lipase crucial to adrenal steroidogenesis ${ }^{37}$.

The stimulatory effect of 9-cis retinoic acid on cortisol secretion and steroidogenic enzyme expression could not be observed in wells co-incubated with ACTH. In fact, cortisol secretion was comparable to levels observed with ACTH alone for 9-cis retinoic acid concentrations up to $1 \mu \mathrm{M}$ as were DAX-1, STAR and CYP17A1 expression. It is tempting to speculate that the reduction in $M C 2 R$ induced by 9 -cis retinoic acid dampens the adrenal response to $\mathrm{ACTH}$, thus overriding its stimulatory effect on spontaneous cortisol secretion. In our previous study on normal adrenal tissue, the stimulatory effect of 9-cis retinoic acid on ACTH-stimulated cortisol secretion and STAR expression was modest or not significant ${ }^{15}$. It stands to reason that the stimulatory effect is abolished in ACTH-dependent adrenal hyperplasia, given the preeminent role of ACTH and, thus, MC2R.

Interestingly, ACTH also increased retinoic acid receptor beta $(R A R B)$ expression and, further, ligand-induced upregulation of both receptor isoforms was enhanced during ACTH/9-cis retinoic acid co-incubation. Of note, $R A R B$ has been shown to be more sensitive than RARA to upregulation by retinoids in some cell models ${ }^{28}$. Given that the adrenal gland itself produces endogenous retinoid acid $^{16}$, these changes could come into play in an intraadrenal retinoic acid-ACTH circuit.

In patients with Cushing's disease, cortisol hypersecretion is driven by ACTH produced by tumoral corticotropes. Although plasma ACTH concentrations are not always markedly elevated, they prove sufficient to determine excess cortisol secretion by the adrenal. In fact, the adrenal $M C 2 R$ is believed to be upregulated in these patients by virtue of long-standing ACTH stimulation and, further, markedly reduced $M C 2 R$ expression underlies 


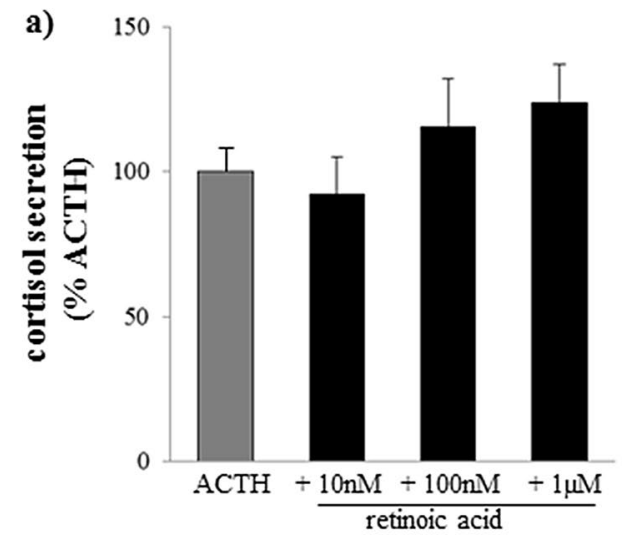

b)

$S T A R$

CYP17A1

$M C 2 R$
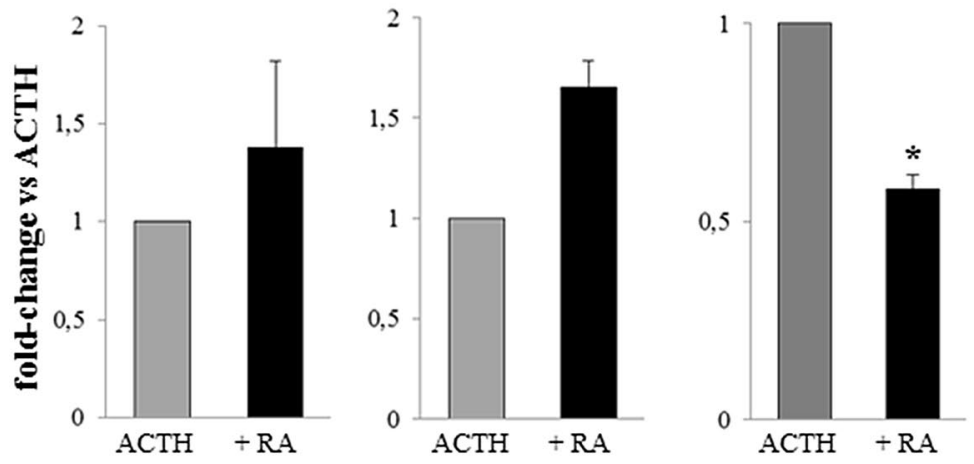

c)

$R A R B$

$R A R A$
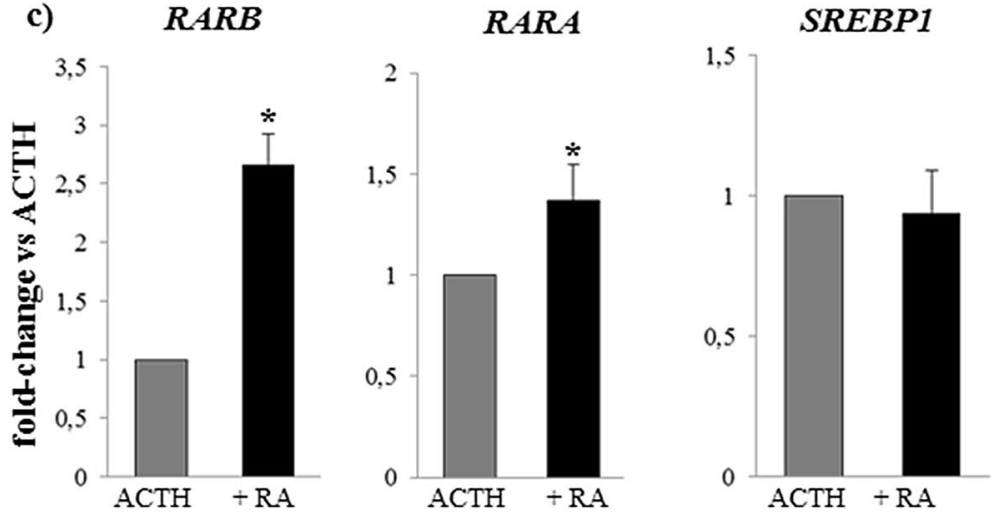

Figure 2. Effect of 9-cis retinoic acid on ACTH-stimulated cortisol secretion and gene expression in adrenal cultures from patients with Cushing's disease. (a) mean ACTH-stimulated cortisol secretion after $24 \mathrm{~h}$ incubation with $10 \mathrm{nM}-1 \mu \mathrm{M}$ 9-cis retinoic acid; (b) expression of STAR, CYP17A1 and MC2R after $24 \mathrm{~h}$ incubation with $10 \mathrm{nM}$ ACTH and $10 \mathrm{nM}$ 9-cis retinoic acid (RA); (c) expression of RARA, RARB and SREBP1 after $24 \mathrm{~h}$ incubation with $10 \mathrm{nM}$ ACTH and $10 \mathrm{nM}$ 9-cis retinoic acid (RA). Data is expressed relative to ACTH-treated wells: equal to $100 \%$ for ACTH-stimulated cortisol secretion and equal to 1 for ACTHstimulated gene expression; Grey bar: $10 \mathrm{nM}$ ACTH, black bars: 9 -cis retinoic acid (RA). ${ }^{*} \mathrm{p}<0.05$ vs ACTH.

the absent cortisol response to ACTH testing in patients with Cushing's disease submitted to surger $\mathrm{y}^{38}$. Along the same line, the reduction of $M C 2 R$ induced by 9-cis retinoic acid could play a major role in its therapeutic efficacy in Cushing's disease. As mentioned above, the decrease in cortisol levels observed in patients treated with both tretinoin ${ }^{11}$ and isotretinoin ${ }^{12}$ appeared greater and not strictly time-related to changes in ACTH concentrations. The decrease in ACTH is expected by virtue of its action in human tumoral corticotropes ${ }^{5,10}$ whereas the observed down-regulation of $M C 2 R$ could contribute to explain a greater decrease in cortisol.

In conclusion, our findings indicate that although 9-cis retinoic acid stimulates unchallenged cortisol secretion, in presence of ACTH the decrease in adrenal ACTH receptor overrides this effect. Thus, an adjunctive, adrenal action could play a role in the efficacy of retinoids in patients with Cushing's disease. 


\section{Material and methods}

Adrenal cultures. Adrenals obtained from 6 patients with Cushing's disease submitted to adrenalectomy were established in culture according to our usual protocols ${ }^{15,39}$. In brief, the adrenal medulla was carefully removed and adrenal cortex fragments were minced, digested in $0.1 \%$ collagenase, plated at approx. 300,000 cells/well, incubated in DMEM supplemented with $10 \%$ fetal bovine serum and antibiotics for 3-5 days to allow attachment.

Treatments and assays. Treatment were performed in DMEM containing $0.1 \%$ BSA. Cells were incubated with $10 \mathrm{nM}, 100 \mathrm{nM}$ and $1 \mu \mathrm{M}$ 9-cis retinoic acid (Sigma Aldrich, St. Louis, USA) with or without $10 \mathrm{nM}$ ACTH for $24 \mathrm{~h}$. Pregnenolone $(10 \mu \mathrm{M})$ was included in the test medium in order to promote steroidogenesis ${ }^{40}$. Both pregnenolone and retinoic acid were dissolved in 100\% ethanol and diluted 1000-fold in DMEM; equal volumes of ethanol were added to control wells. Treatments were performed in triplicate for each adrenal specimen. Cortisol in medium was measured using Coat-A-Count radioimmunoassay (Siemens Healthcare Diagnostics, Erlangen, Germany) and normalized to unchallenged or ACTH-stimulated wells, respectively, given the considerable variability in cortisol medium concentrations among specimens (from $360 \mathrm{ng} / \mathrm{ml}$ to $990 \mathrm{ng} / \mathrm{ml}$ after $24 \mathrm{~h}$ incubation).

Quantitative real-time PCR. RNA was extracted from plated cells using TRIzol reagent (Life Technologies, Carlsbad, USA) according to the manufacturer's instruction. The amount and quality of RNA were checked on nanophotometer (Implen $\mathrm{GmbH}$, München, Germany) and 100 ng RNA reverse-transcribed with Superscript Vilo cDNA Synthesis Kit (Life Technologies, Carlsbad, USA). Quantitative Real-Time PCR was performed on a 7900 HT sequence Detection System (Applied Biosystems, Foster City, USA), using the Platinum Quantitative PCR Supermix-UDG with ROX (Life Technologies, Carlsbad, USA) and TaqMan assays. The following genes were evaluated: STAR Hs00264912_m1, MC2R Hs00300820_s1, NR1H3 (LXRa) Hs00172885_ m1, NR0B1 (DAX-1) Hs00230864_m1, PPARD Hs00987011_m1, NR2F1 (COUP-TF1) Hs00818842_m1, CYP17A1 Hs01124136_m1, LIPE Hs00943410_m1, RARA Hs00940446_m1, RARB Hs00977140_m1, mt-ND1 Hs02596873_s1, mt-ND6 Hs02596879_g1, NR5A1 (SF-1) Hs00610436_m1, SREBP1 Hs01088679_g1 and normalized to RPLP0 Hs99999902_m1. Expression data was analyzed as $2^{-\Delta \Delta \mathrm{Ct}}$ and expressed as fold change vs control or ACTH. Changes in gene expression were evaluated in wells treated with $10 \mathrm{nM} 9$-cis retinoic acid.

Statistical analyses. Data is expressed as mean \pm standard error of the mean (S.E.M.) relative to unchallenged or ACTH-stimulated wells for each adrenal specimen. Comparisons were performed using Wilcoxon's signed-rank test and statistical significance accepted at $\mathrm{p} \leq 0.05$.

Study approval. The study was approved by the Ethical Committee of the Istituto Auxologico Italiano (project \#02C402) and carried out according to guidelines established by the Declaration of Helsinki.

Informed consent. Informed consent for secondary use of surgical tissues obtained from patients by the referring physician prior to surgery.

\section{Data availability}

The datasets generated during the current study are available from the corresponding author on reasonable request.

Received: 1 March 2021; Accepted: 4 June 2021

Published online: 12 July 2021

\section{References}

1. Dihazi, G. H. et al. Proteomic characterization of adrenal gland embryonic development reveals early initiation of steroid metabolism and reduction of the retinoic acid pathway. Proteome Sci. 13, 6-18 (2015).

2. El Zein, R. M. et al. Retinoic acid receptor $\alpha$ as a novel contributor to adrenal cortex structure and function through interactions with Wnt and Vegfa signalling. Sci. Rep. 9, 14677 (2019).

3. Dollè, P., Niederreither, K.The Retinoids. Biology, Biochemisty, and Disease. (eds. Dollè, P., Niederreither, K), 1-574 (Wiley, 2015).

4. Giuli, M. V. et al. Current trends in ATRA delivery for cancer therapy. Pharmaceutics 12, 707 (2020).

5. Páez Pereda, M. et al. Retinoic acid prevents experimental Cushing's syndrome. J. Clin. Invest. 108, 1123-1131 (2001).

6. Szabó, D. R. et al. Antitumoral effects of 9-cis retinoic acid in adrenocortical cancer. Cell. Mol. Life Sci. 71, 917-932 (2014).

7. Labeur, M., Páez Pereda, M., Arzt, E. \& Stalla, G. K. Potential of retinoic acid derivatives for the treatment of corticotroph pituitary adenomas. Rev. Endocr. Metab. Disord. 10, 103-109 (2009).

8. Giacomini, D. et al. Bone morphogenetic protein-4 inhibits corticotroph tumor cells: Involvement in the retinoic acid inhibitory action. Endocrinology 147, 247-256 (2006).

9. Saito-Hakoda, A. et al. Effects of RXR agonists on cell proliferation/apoptosis and ACTH secretion/Pomc expression. PLoS ONE 10, $\mathrm{e} 0141960$ (2015)

10. Occhi, G. et al. Activation of the dopamine receptor type-2 (DRD2) promoter by 9-cis retinoic acid in a cellular model of Cushing's disease mediates the inhibition of cell proliferation and ACTH secretion without a complete corticotroph-to-melanotroph transdifferentiation. Endocrinology 155, 3538-3549 (2014).

11. Pecori Giraldi, F. et al. Potential role for retinoic acid in patients with Cushing's disease. J. Clin. Endocrinol. Metab. 97, 3577-3583 (2012).

12. Vilar, L. et al. The role of isotretinoin therapy for Cushing's disease: Results of a prospective study. Int. J. Endocrinol. 2016, 8173182 (2016).

13. Pecori Giraldi, F. \& Ambrogio, A. G. Variability in laboratory parameters used for management of Cushing's syndrome. Endocrine 50, 580-589 (2015). 
14. Fuertes, M. et al. New insights in Cushing disease treatment with focus on a derivative of Vitamin A. Front. Endocrinol. 9, 262 (2018).

15. Sesta, A. et al. Effect of retinoic acid on human adrenal corticosteroid synthesis. Life Sci. 151, 277-280 (2016).

16. Haselbeck, R. J., Ang, H. L., Deltour, L. \& Duester, G. Retinoic acid and alcohol/retinol dehydrogenase in the mouse adrenal gland: A potential endocrine source of retinoic acid during development. Endocrinology 138, 3035-3041 (1997).

17. Zanaria, E. et al. An unusual member of the nuclear hormone receptor superfamily responsible for X-linked adrenal hypoplasia congenita. Nature 372, 635-641 (1994).

18. Manna, P. R. et al. Synergistic activation of steroidogenic acute regulatory protein expression and steroid biosynthesis by retinoids: Involvement of cAMP/PKA signaling. Endocrinology 155, 576-591 (2014).

19. Lee, H. K. et al. Retinoic acids up-regulate steroidogenic acute regulatory protein gene. Mol. Cell. Endocrinol. 148, 1-10 (1999).

20. Tucci, P., Cione, E. \& Genchi, G. Retinoic acid-induced testosterone production and retinoylation reaction are concomitant and exhibit a positive correlation in Leydig (TM-3) cells. J. Bioenerg. Biomembr. 40, 111-115 (2008).

21. Zsippai, A. et al. mRNA and microRNA expression patterns in adrenocortical cancer. Am. J. Cancer Res. 1, 618-628 (2011).

22. Lin, $\mathrm{Y}$. W. et al. 9-cis retinoic acid induces retinoid $\mathrm{X}$ receptor localized to the mitochondria for mediation of mitochondrial transcription. Biochem. Biophys. Res. Commun. 377, 351-354 (2008).

23. Yacqub-Usman, K., Duong, C. V., Clayton, R. N. \& Farrell, W. E. Preincubation of pituitary tumor cells with the epidrugs zebularine and trichostatin A are permissive for retinoic acid-augmented expression of the BMP-4 and D2R genes. Endocrinology 154, 1711-1721 (2013).

24. Uruno, A. et al. Retinoic acid receptor- $\alpha$ up-regulates proopiomelanocortin gene expression in AtT20 corticotroph cells. Endocr. J. 61, 1105-1114 (2014).

25. Bertagna, X. Effects of chronic ACTH excess on human adrenal cortex. Front. Endocrinol. 8, 43-49 (2017).

26. Miller, W. L. \& Auchus, R. J. The molecular biology, biochemistry, and physiology of human steroidogenesis and its disorders. Endocrine Rev. 32, 81-151 (2011).

27. Lefevre, A. et al. Regulation by retinoids of luteinizing hormone/chorionic gonadotropin receptor, cholesterol side-chain cleavage cytochrome P-450, 3 beta-hydroxysteroid dehydrogenase/delta (5-4)-isomerase and 17 alpha-hydroxylase/C17-20 lyase cytochrome P-450 messenger ribonucleic acid levels in the K9 mouse Leydig cell line. Mol. Cell. Endocrinol. 106, 31-39 (1994).

28. Clifford, J. L., Petkovich, M., Chambon, P. \& Lotan, R. Modulation by retinoids of mRNA levels for nuclear retinoic acid receptors in murine melanoma cells. Mol. Endocrinol. 4, 1546-1555 (1990).

29. Roder, K., Zhang, L. \& Schweizer, M. SREBP-1c mediates the retinoid-dependent increase in fatty acid synthase promoter activity in HepG2. FEBS Lett. 581, 2715-2720 (2007).

30. Zazopoulos, E., Lalli, E., Stocco, D. M. \& Sassone-Corsi, P. DNA binding and transcriptional repression by DAX-1 blocks steroidogenesis. Nature 390, 311-315 (1997).

31. Shea-Eaton, W. K. et al. Sterol regulatory element binding protein-1a regulation of the steroidogenic acute regulatory protein gene. Endocrinology 142, 1525-1533 (2001).

32. Ozbay, T. et al. Cyclic adenosine 5'-monophosphate-dependent sphingosine-1-phosphate biosynthesis induces human CYP17 gene transcription by activating cleavage of sterol regulatory element binding protein 1. Endocrinology 147, 1427-1437 (2006).

33. Picard-Hagen, N. et al. Glucocorticoids enhance corticotropin receptor mRNA levels in ovine adrenocortical cells. J. Mol. Endocrinol. 19, 29-36 (1997).

34. Hofland, J. et al. Melanocortin 2 receptor-associated protein (MRAP) and MRAP2 in human adrenocortical tissues: Regulation of expression and association with ACTH responsiveness. J. Clin. Endocrinol. Metab. 97, E747-E754 (2012).

35. Xing, Y., Parker, C. R., Edwards, M. \& Rainey, W. E. ACTH is a potent regulator of gene expression in human adrenal cells. J. Mol. Endocrinol. 45, 59-68 (2010).

36. Clark, A. J. \& Weber, A. Adrenocorticotropin insensitivity syndromes. Endocrine Rev. 19, 828-843 (1998).

37. Kraemer, F. B. et al. Hormone-sensitive lipase is required for high-density lipoprotein cholesteryl ester-supported adrenal steroidogenesis. Mol. Endocrinol. 18, 549-557 (2004).

38. Alwani, R. A. et al. Rapid decrease in adrenal responsiveness to ACTH stimulation after successful pituitary surgery in patients with Cushing's disease. Clin. Endocrinol. 75, 602-607 (2011).

39. Pecori Giraldi, F. et al. Stimulatory effect of SOM230 on human and rat adrenal corticosteroid secretion in vitro. Gen. Comp. Endocrinol. 178, 436-439 (2012).

40. Hornsby, P. J. \& McAllister, J. M. Culturing steroidogenic cells. Methods Enzymol. 206, 371-380 (1991).

\section{Acknowledgements}

The authors acknowledge support from the University of Milan through the APC initiative.

\section{Author contributions}

Conceptualization: F.P.G. and L.C.; Data curation: A.S., L.T., M.F.C, and F.P.G.; Formal analysis and data interpretation: A.S., L.T., M.F.C, and F.P.G.; Draft preparation: A.S. and L.T.; Manuscript revision and editing: F.P.G. and L.C. All authors reviewed and approved the submitted version.

\section{Competing interests}

The authors declare no competing interests.

\section{Additional information}

Correspondence and requests for materials should be addressed to F.P.G.

Reprints and permissions information is available at www.nature.com/reprints.

Publisher's note Springer Nature remains neutral with regard to jurisdictional claims in published maps and institutional affiliations. 
(c) (i) Open Access This article is licensed under a Creative Commons Attribution 4.0 International cc) License, which permits use, sharing, adaptation, distribution and reproduction in any medium or format, as long as you give appropriate credit to the original author(s) and the source, provide a link to the Creative Commons licence, and indicate if changes were made. The images or other third party material in this article are included in the article's Creative Commons licence, unless indicated otherwise in a credit line to the material. If material is not included in the article's Creative Commons licence and your intended use is not permitted by statutory regulation or exceeds the permitted use, you will need to obtain permission directly from the copyright holder. To view a copy of this licence, visit http://creativecommons.org/licenses/by/4.0/.

(C) The Author(s) 2021 